\title{
Design and Fabrication of Microstrip Patch Antenna at 2.4 Ghz for WLAN Application using HFSS
}

\author{
Shera Prabjyot Singh ${ }^{1}$, Ashish Singh ${ }^{2}$, Deepak Upadhyay ${ }^{3}$, Sunilkumar Pal $^{4}$, \\ Mahesh Munde ${ }^{5}$ \\ 1, 2, 3, 4, 5 (Department of Electronics \& Telecommunications. Xavier's Technical Institute, Mumbai-400016)
}

\begin{abstract}
In this paper, a rectangular microstrip patch antenna is designed using HFSS software. The designed antenna has a resonating frequency of $2.4 \mathrm{GHz}$ which is applicable to Wireless Local Area Network (WLAN). This paper shows the design considerations of the proposed antenna as well as the simulated results of the same. The design is made on FR-4 Epoxy material used as a dielectric material with its dielectric constant $\varepsilon_{r}=4.4$ and thickness of $1.5 \mathrm{~mm}$. The proposed antenna is then fabricated on the basis of the simulated design in HFSS simulation software. After fabricating the MSA, the fabricated results were taken and are shown in the paper. The simple structured configuration and low profile of the proposed antenna makes the fabrication process easy and also suitable for the application in the WLAN.
\end{abstract}

Keywords - Micro Strip Antenna (MSA); High Frequency Structure Simulator (HFSS); WLAN; Patch; Return Loss; dielectric.

\section{INTRODUCTION}

Micro strip antenna was first introduced in the 1950s. However, the technology of Printed Circuit Board (PCB) was later introduced in 1970s. Therefore, from that time MSA had become a very common antenna having wide range of applications due to their advantages light weight, low profile, low cost, planar configuration and many more.[1] MSAs are widely used in Radio-Frequency Identification (RFID), Broadcast radio, mobile systems, Global Positioning System (GPS), satellite communication, television systems, multiple-input multiple output (MIMO) systems, vehicle collision avoidance system, surveillance system, direction founding, radar systems, remote sensing, missile guidance, and so on [2].

Because of micro strip patch antenna's many unique and attractive properties, there seems to be little doubt that it will continue to find many applications in the future. Its properties includes, light weight, low profile, easy fabrication, compact and conformability to mounting structure [2] [3].

In this design, we are concentrating on rectangular microstrip patch antenna which consists of rectangular patch of length [L1] and width [W2] of the patch. The proposed antenna works on the wireless local area network (WLAN) frequency of $2.4 \mathrm{GHz}(2400-2484 \mathrm{MHz})$ which is based on IEEE $802.11 \mathrm{~b}$ for WLAN applications [2][3]. The Substrate material used is FR-4 Epoxy which has permittivity i.e. its dielectric constant $\varepsilon_{r}=4.4$ which lies in the specified range of $2 \leq \varepsilon_{r} \leq 12$ [4][5]

\section{PROPOSED ANTENNA GEOMETRY}

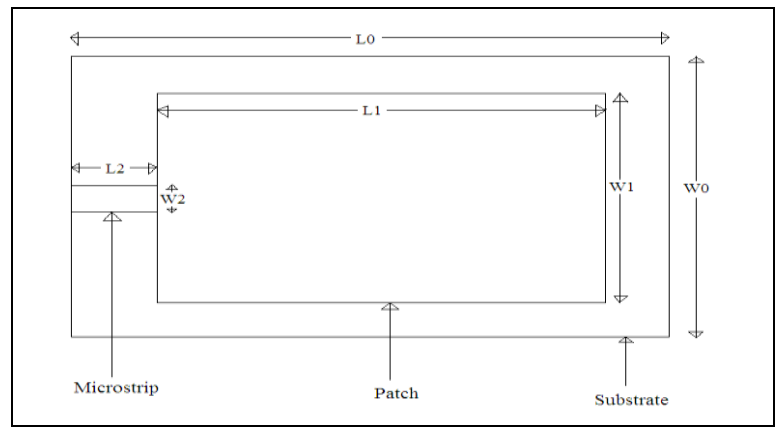

Fig1: Antenna Geometry 
Table I design parameters of rectangular MSA

\begin{tabular}{|c|c|}
\hline Parameters & Values (in mm) \\
\hline H & 1.5 \\
\hline L0 & 47.04 \\
\hline W0 & 38.48 \\
\hline L1 & 38.04 \\
\hline W1 & 29.48 \\
\hline L2 & 5.2 \\
\hline W2 & 1 \\
\hline
\end{tabular}

Fig.1 shows the proposed antenna geometry consisting of dielectric substrate, patch as well as microstrip feed line. The rectangular patch is separated from the ground plane with FR-4 Dielectric substrate with the above shown dimensions. While table I shows the respective design parameter values of the proposed antenna.

\section{ANALYSIS AND DESIGN EQUATIONS}

All the dimensions of the MSA shown in the table were calculated by using the rectangular patch design equations as shown below [7] [8]: -

1. Width of Patch $(W)=\frac{c}{2 f_{r_{x}} \sqrt{\frac{\left.\varepsilon_{Y}+1\right]}{q}}}$

2. $\epsilon_{\text {eff }}=\frac{\varepsilon_{r}+1}{2}+\frac{z_{r}-1}{2}\left[1+\frac{12 h}{W}\right]^{-\frac{1}{2}}$

3. $L_{\text {eff }}=\frac{C}{2 f_{r} \sqrt{s_{\text {eff }}}}$

4. $\Delta L=0.412 h \frac{\left(s_{\text {sff } f}+0.3\right)\left(\frac{W}{h}+0.264\right)}{\left(s_{\text {sff }}-0.258\right)\left(\frac{W}{h}+0.8\right)}$

5. Length of Patch $(\mathrm{L})=L_{\text {eff }}-2 \Delta L$

6. Length of Substrate $\left(L_{g}\right)=6 h+L$

7. Width of Substrate $\left(W_{g}\right)=6 h+W$

These all equations are to be used for predicting the resonant frequency, width, patch thickness and dielectric constant. The width of the rectangular MSA is given by [7];

$$
W=\frac{C}{2 f_{r} \sqrt{\frac{\left(\varepsilon_{r}+1\right)}{2}}}
$$

Where, $\mathrm{C}$ is the speed of light, $f_{r}$ is the resonant frequency, $\varepsilon_{r}$ and is the Relative dielectric constant of the substrate. Now by substituting the values of $\mathrm{C}=3 \times 10^{8} \mathrm{~m} / \mathrm{s}, \mathrm{F}=2.4 \mathrm{GHz}$ and $\varepsilon_{r}=4.4 \mathrm{~W}=38.03 \mathrm{~mm}$. But the table shows the optimized value of each and every dimensions of the proposed antenna by using trial and error method. Thus width of the patch is taken $38.48 \mathrm{~mm}$.

The effective dielectric constant $\epsilon_{\text {eff }}$ is given by;

$$
\epsilon_{\text {eff }}=\frac{\varepsilon_{r}+1}{2}+\frac{\varepsilon_{r}-1}{2}\left[1+\frac{12 h}{W}\right]^{-\frac{1}{2}}
$$


Here, $h$ is the height of the substrate i.e. FR-4 Epoxy material, $\mathrm{W}$ is width of the patch, $\varepsilon_{r}$ is the dielectric constant of the substrate. Hence by substituting all these values where $h=1.5 \mathrm{~mm}$ we get the value of the effective dielectric constant as $\epsilon_{\text {eff }}=4.10$.

The effective length $L_{\text {eff }}$ is calculated by;

$$
L_{\text {eff }}=\frac{C}{2 f_{r} \sqrt{\varepsilon_{\text {eff }}}}
$$

Hence by substituting the values of $\mathrm{C}$ and $\epsilon_{\text {eff }}$ above, the effective length will be $L_{\text {eff }}=30.86 \mathrm{~mm}$.

The difference in length $\Delta L$, which is a function of the effective dielectric constant and the ratio of width to height is given as;

$$
\Delta L=0.412 h \frac{\left(\varepsilon_{\text {eff }}+0.3\right)\left(\frac{W}{h}+0.264\right)}{\left(\varepsilon_{\text {eff }}-0.258\right)\left(\frac{W}{h}+0.8\right)}
$$

Again by substituting all the required values we get the difference in length $\Delta L=0.6934 \mathrm{~mm}$.

Finally, the actual length of the patch which is given as; $\mathrm{L}=L_{\text {eff }}-2 \Delta L$

Hence, $\mathrm{L}=29.4732 \mathrm{~mm}$. This is again optimized to $29.48 \mathrm{~mm}$. After calculating the values of all the material which are used in the MSA design we simulated that antenna design on the HFSS software and got the simulated results.

\section{ANTENNA DESIGNED IN HFSS}

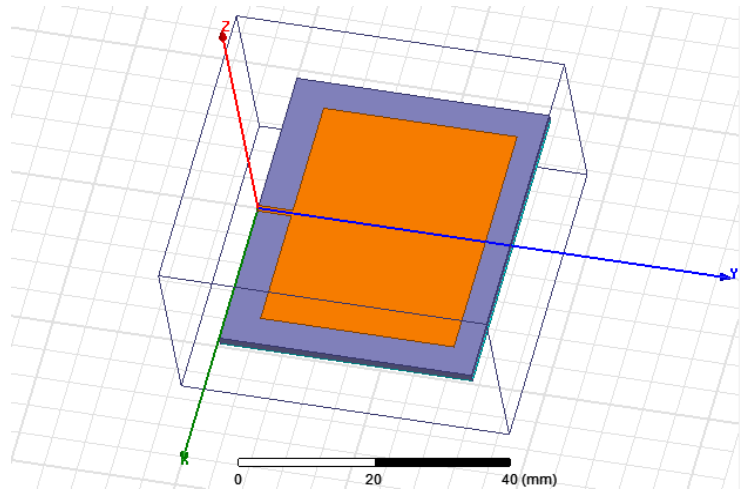

Fig.3: Proposed rectangular microstrip patch antenna using HFSS Software

\section{Simulated ReSUlts In HFSS}

When we completed the design part of the proposed antenna we got the simulated results of the antenna which includes return loss (S11 parameter), VSWR, 2D radiation pattern as well as 3D radiation pattern.

In fig. 4 we could observe that the designed antenna is providing $-12.0505 \mathrm{~dB}$ return loss at the resonant frequency of $2.4 \mathrm{GHz}$. And in fig. 5 we got voltage standing wave ratio with minimum value of 0.5550 at $2.3680 \mathrm{GHz}$. 


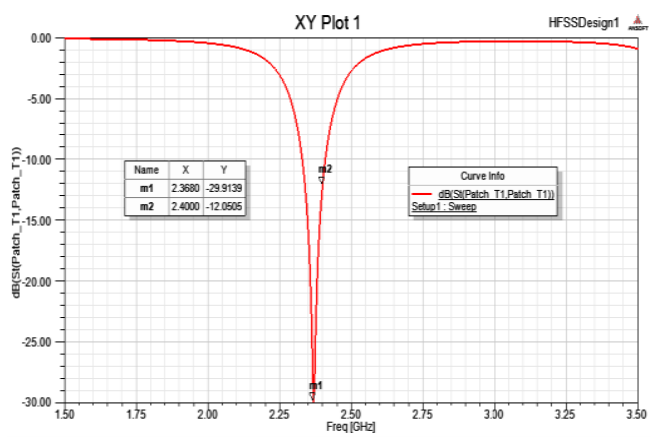

Fig.4: S11 Parameter

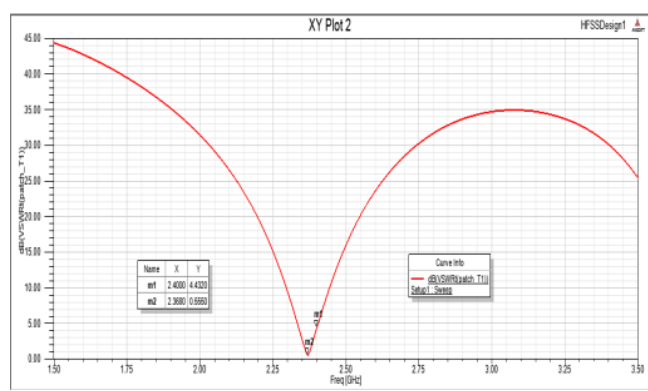

Fig.5: VSWR

Fig. 6, 7 shows the 2D radiation pattern and 3D radiation pattern. Radiation pattern refers to the direction of the electromagnetic waves radiates away from the antenna. For these results we set the solution frequency to $2.4 \mathrm{GHz}$ for the maximum number of 15 adaptive solutions with maximum delta $\mathrm{S}$ of 0.02 . The radiation pattern for the proposed antenna is omnidirectional and also this antenna can be used at WLAN application.
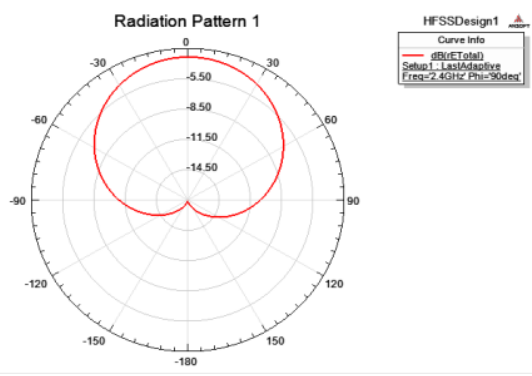

Fig.6: 2D Radiation Pattern
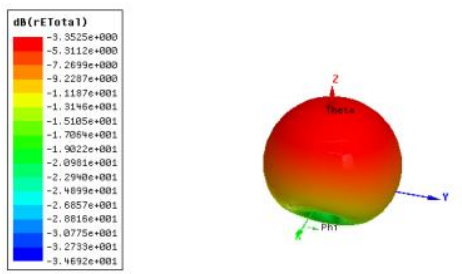

Fig.7: 3D Radiation Pattern

\section{FABRICATION OF MSA}

As the design of the proposed antenna is analyzed and simulated on the HFSS simulation software. That design is to be converted into another format which can include many formats such as: - Gerber, AutoCAD DXF, BMP 
file and many more. We have used DXF file format and given it to the automatic antenna fabricating machine and thus fabricated the MSA as shown in fig. 8 below.

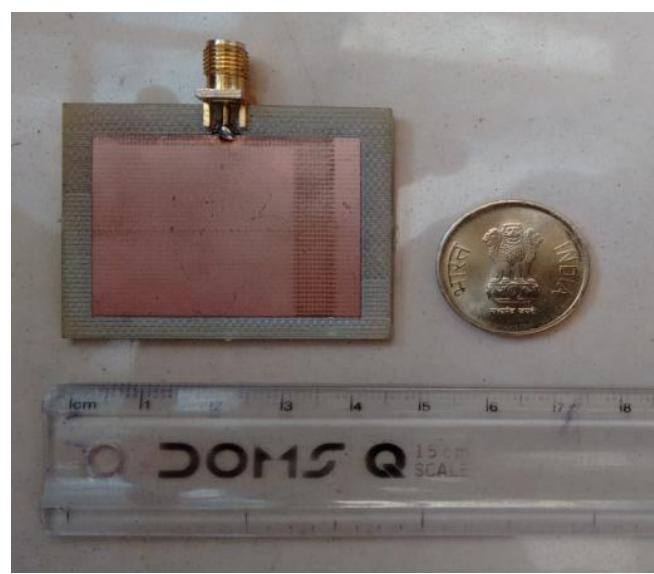

Fig. 8: Fabricated MSA

\section{FABRICATED RESUlts}

Hence we got the results of the fabricated antenna using the Vector Network Analyzer (VNA) as shown in fig. 9,10 and 11 .

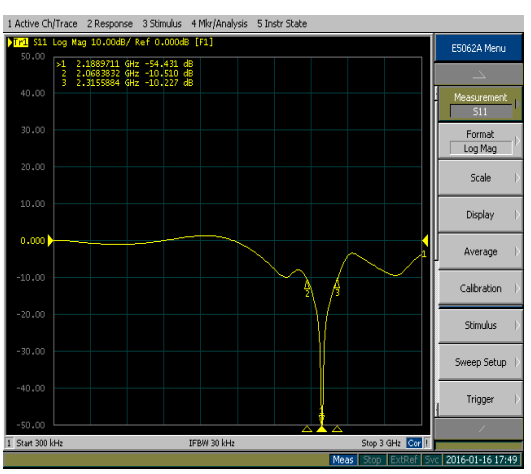

Fig.11: Smith Chart

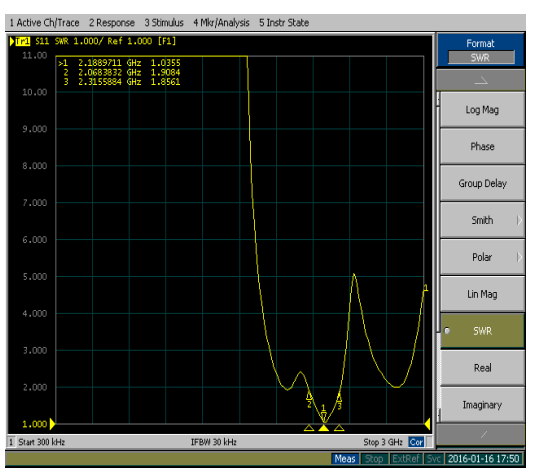

Fig.9: Return Loss (S11 Parameter)

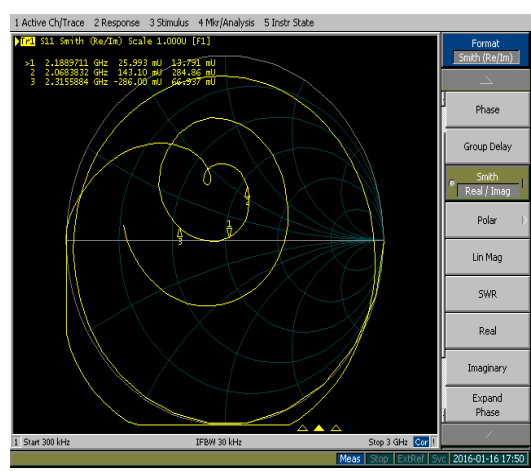

Fig.10: VSWR

Fig. 9 shows the return loss (S11 Parameter) where at $2.19 \mathrm{GHz}$ we are getting maximum return loss of 54.431 $\mathrm{dB}$, whereas the bandwidth is approx. 200MHz. Fig. 10 shows the VSWR plot of the fabricated antenna which gives minimum value at $2.19 \mathrm{GHz}$ of 1.0355 .

\section{CONCLUSION}

The proposed antenna is having the return loss of $-12.0505 \mathrm{~dB}$ at $2.4 \mathrm{GHz}$. The designed MSA has been simulated on HFSS simulation software. Also for this antenna a sufficient bandwidth is introduced via the microstrip feed line at the desired resonant frequency of $2.4 \mathrm{GHz}$ is achieved. As mentioned above the designed MSA is optimized such that it covers WLAN. The proposed antenna is a low profile antenna thus it is very compact, easy to fabricate and is fed by a microstrip feed line which makes it an attractive structure for current as well as future WLAN applications. The fabrication process is easy and cost effective. As observed the fabricated results are much finer as compared to the simulated one. 


\section{ACKNOWLEDGMENT}

We would like to extend our gratitude and sincere thanks to the authors of this paper, our institute Principal Dr. Shivaji Ghungrad for his help and financial support that he gave us. We sincerely thanks our supervisor Mr. Mahesh Munde for his exemplary guidance and encouragement during our work.

\section{REFERENCES}

[1] Tanish Narang; Shubhangi jain; "Microstrip Patch Antenna- A Historical Perpective of the Development",Conference on Advances in Communication and Control Systems 2013 (CAC2S 2013).

[2] Ogunlade Michael Adegoke; Ismael Saad Eltoum; “Analysis and Design of Rectangular Microstrip Patch Antenna AT 2.4GhzWLAN Applications", International Journal of Engineering Research \&Technology (IJERT) ISSN: 2278-0181Vol. 3 Issue 8, August - 2014.

[3] J. R. James, P.S. Hall. Handbook of microstrip antennas, I.E.E. Electromagnetic Waves Series 28- Peter Pereginus LTD, 1989.

[4] C. A. Balanis, “Antenna Theory-Analysis and Design,” 2nd ed., J. Peters, John Wiley and Sons, pp. 728-730.

[5] Girish Kumar, K.P. Ray, "Broadband microstrip antennas", Aretch House 2003.

[6] R.J. Mailloux, J.F. Mcllvenna and N.P. Kemweis-Microstrip Array Technology IEEE Transactions on Antennas and Propagation, Vol. 29, No.1, January 1981.

[7] Ansoft Corporation, HFSS User's Guide, version 10 \&12, Ansoft Corporation,Pittsburgh,CA,20

[8] Nandini Ammanagi, Rahul Khadilkar, Akash Harwani, Disha Budhlani, Disha Dembla; "Comparison of the performance of Microstrip Antenna at 2.4GHz Using Different Substrate Materials", International Journal of Engineering and Advanced Technology (IJEAT) ISSN: 2249 - 8958, Volume-3, Issue-4, April 2014. 